\title{
An assessment of the health care system for diabetes in Addis Ababa, Ethiopia
}

\author{
Yeweyenhareg Feleke ${ }^{1}$, Fikre Enquselassie ${ }^{2}$
}

\begin{abstract}
Background: During the past decade, diabetes mellitus has emerged as an important clinical and public health problem through out the world. WHO estimated the number of cases of diabetics in Ethiopia to be about 800,000 in 2000, and projected that it would increase to about 1.8 million by the year 2030. Care for diabetic patients may require close and sustained support from a health care team, adequate financial resources, and advanced patient knowledge and motivation. In this respect, there is lack of information in the country.

Objective: This study was conducted with the aim of assessing the characteristics of the health care system for diabetic patients, how diabetic patients are cared for including medical care and adequacy of facilities for the prevention of complications and outcomes at primary health care and secondary health care levels.

Methods: An assessment of the characteristics of the health care system (structure) for diabetic patients was conducted in 21 health centres (primary health care level) and 5 regional hospitals (secondary health care level) in Addis Ababa. Furthermore, a total of 106 diabetic patients drawn from six out of the 21 health centres and another 123 diabetic patients drawn from three of the six hospitals were consecutively interviewed.

Results: All the Regional hospitals and one of the health centres were running established diabetic referral clinics. Similarly, a lack of professionals was observed in all the health institutions in general and the health centres, in particular. Only $21 \%$ of patients had access for blood glucose monitoring at the same health institutions. The emphasis given for diabetic education (24\%) was less than expected. Only $11(5 \%)$ of diabetic patients were able to do self blood glucose monitoring at home. Fifty one percents of patients didn't have urine analysis, BUN, creatinine and lipid profile in the previous 1-2 years. None of diabetic patients had haemoglobin Alc (HbAlc) determination. Nearly $75 \%$ of the patients required admissions directly or indirectly due to uncontrolled diabetes. About $87 \%$ of the diabetics had regular follow ups at their respective health centres and hospitals. Hypertension (34\%), diabetes related eye disease $(33 \%)$ and renal disease $(21 \%)$ were the major associated illnesses observed among the diabetics. Sixty-six patients $(23 \%)$ had a total of about 131 admissions.

Conclusion: Although there is a well-established health infrastructure for diabetics care in Addis Ababa, the diabetic care is below the acceptable standard. The finding of this study may, thus, help to clarify issues related to potential changes in the health care system dealing with diabetes and for strengthening the referral system for diabetes health care. [Ethiop;J.Health Dev. 2005;19(3):203-210]
\end{abstract}

\section{Introduction}

During the past decade, diabetes mellitus has emerged as an important clinical and public health problem through out the world. At present, Diabetes is a leading cause of blindness, end stage renal disease and stroke that are two to five times more common among diabetic patients (1). Diabetes is a growing problem in the developing world including Africa. The International Diabetes Federation (IDF) predicts that most new cases of diabetes will occur in developing nations. According to $\mathrm{WHO}$ the rise in cases over the next few decades will approach $200 \%$ in developing, and $45 \%$ in developed countries respectively. The prevalence of diabetes in traditional rural African communities is less than $1 \%$ but escalates up to $30 \%$ in cities (2).

No population-based prevalence study exists in Ethiopia but from hospital based studies it can be seen that the prevalence of diabetes admission has increased from $1.9 \%$ in 1970 to $9.5 \%$ in 1999 of all medical admissions $(3,4,5,6,7)$. WHO estimated the number of diabetics in Ethiopia to be about 800,000 cases by the year 2000 , and the number is expected to increase to 1.8 million by 2030 (8).

Achieving and maintaining normoglyceamia, blood pressure and lipids levels in both Type 1 and Type 2 diabetes may require close ongoing support from a health care team, financial resources, and advanced patient knowledge and motivation. Providing this level of management to all individuals with diabetes may require major changes in the health care system and the patient self care procedure $(9,10,11)$.

Motalla, Okoro et al from Africa show that the prevention of diabetes mellitus and its complication in Africa are impeded by an inadequate supply of medications, absence of educational programs and lack of health care facilities and providers $(12,13)$.

${ }^{1}$ Endocrinology and Metabolism Unit, Department of Internal Medicine, Faculty of Medicine, Addis Ababa University, P.O. Box 23119 Code 1000, Email: yeweyeharegf@yahoo.com, Addis Ababa, Ethiopia; ${ }^{2}$ Department of Community Health, Faculty of Medicine, Addis Ababa University, Addis Ababa, Ethiopia 
The ultimate purpose of quality assessment in health care is to improve the effectiveness of health service programs. Quality assessment not only shows the outcome or accomplishment of services and programs in relation to the standard but it may also suggest a point or points of difficulty and efforts that can be focused on to identify the links in the chain. The quality assessment of health care considers the three-parts approach (i) the structure: which includes the attributes of the material resources, human resources and organizational structures, (ii) the process which denotes what is actually done in providing and receiving care e.g. making a diagnosis and implementing treatments and (iii) the outcome which denotes the effect of care on the health status of the patient and the general population $(14,15)$.

This study assessed the characteristics of the health care system for diabetic patients in Addis Ababa, how diabetic patients are cared for; including medical care and adequacy for the prevention of complications at primary health care and secondary health care levels and the outcome of health care services for diabetic patients.

\section{Patients and methods}

A descriptive cross-sectional study was conducted at 21 health centres (primary health care level) and 5 Regional Hospitals (secondary health care level) in Addis Ababa, Ethiopia from February 2002 to July 2003.

An assessment of the characteristics of the health care system (the structure) for diabetic patients was conducted in all the five Regional Hospitals (namely Zewditu Memorial, Yekatit 12, Menilik II, St. Paul's and Ras Desta Dametew) and 21 Health centres (namely Addis Ketema, Akaki, Arada, Beleteshachew, Cazanchize, Charkose, Entoto, Gulele, Kaliti, Kotebe, Yeka, Lideta, Shuromeda, T/Haimanot, and Woredas 13, 17, 18, 19 23, 24, and 25).

Diabetic patient care and the medical care adequacies for the prevention of complications and outcomes were evaluated in six health centres and three regional hospitals randomly selected from the total of 21 health centres and five regional hospitals respectively. A standard checklist was used to assess the equipment and supplies of the hospitals and health centres.

Addis Ababa is divided in to six Zones and one health centre was taken from each Zone using the random sampling method. The three hospitals were selected randomly. A total of 106 diabetic patients participated from the six health centres, and 123 diabetic patients were taken from the selected regional hospitals. Consecutive diabetic patients who came on the day of the study were included in the study, after obtaining informed consent from each patient.

Diabetes was diagnosed based on the standard definition, i.e when fasting blood sugar level is $\geq 126 \mathrm{mg} / \mathrm{dl}$ or random blood sugar $\geq 200 \mathrm{mg} / \mathrm{dl}$ or 2 hours oral glucose test value $\geq 200 \mathrm{mg} / \mathrm{dl}$, as confirmed on a subsequent day by any one of the three methods (16). Two types of questionnaires were applied to collect the data. The first one was to assess the health care system, which consists of information regarding the availability, and adequacy of basic and minimum requirements in terms of equipment, drug, materials and manpower $(17,18,19)$. The second one was to assess the status of diabetic care, which consists of identifying diabetes patients, their mode of diagnosis and treatment, as well as follow up and outcome. Data were collected by trained diabetic nurse specialists from the responsible health professionals (nurses, medical directors) and diabetic patients using interviewing techniques.

The study was approved by the Faculty Research and Publication Committee (FRPC), Addis Ababa University. Permission was obtained from the region 14 Health Bureau to conduct the study at the health centres and Referral hospitals.

Data was entered and processed using the SPSS 11.5 version statistical package and descriptive statistics were used.

\section{Results}

\section{Health care system (structure)}

A total of 21 health centres and five referral hospitals were included in the study. The health centres and hospitals serve a total of 2.7 million people.

Table 1 shows the availability of the investigation and treatment facilities including professionals. All the hospitals and health centres had height and weight scales, blood pressure measurement apparatus and stethoscopes. On the other hand, BUN and creatinine, lipids determination, insulin and insulin syringes were not available in all of the health centres. In addition to this, ECG machines, X- ray machines and culture facilities were not available in all the health centres. Tuning fork was available in only two health centres and hammers were available in four health centres.

The average number of nurses, laboratory technicians and doctors per health centre were 8,2 and 2 respectively. The corresponding average figures per hospital were 64, 10 and 21 respectively. Diabetic patients were managed by a general practitioner at the health centre and an internist at referral hospital levels. All of the hospitals and only one of the health centres had established diabetic referral clinics.

About 30-102 diabetic patients have had follow ups each week in the five Referral hospitals. Very few of the 
in the studied health institutions, Addis Ababa, 2003.

\begin{tabular}{|c|c|c|}
\hline Variables & Hospitals & Health Centres \\
\hline $\begin{array}{l}\text { Laboratory tests } \\
\text { Hb, WBC, ESR } \\
\text { Fasting Blood Sugar } \\
\text { Cllinitest } \\
\text { BUN \& Creatinine } \\
\text { Lipid } \\
\text { HbA1c }\end{array}$ & $\begin{array}{r}\text { All } \\
\text { All } \\
\text { All } \\
\text { All } \\
\text { All } \\
\text { None }\end{array}$ & $\begin{array}{r}18 / 21 \\
10 / 21 \\
9 / 21 \\
\text { None } \\
\text { None } \\
\text { None }\end{array}$ \\
\hline $\begin{array}{l}\text { Specific drugs for diabetes management } \\
\text { Insulin } \\
\text { Insulin syringes } \\
\text { OHA }\end{array}$ & $\begin{array}{l}\text { All } \\
\text { All } \\
\text { All }\end{array}$ & $\begin{array}{r}\text { None } \\
\text { None } \\
9 / 21\end{array}$ \\
\hline $\begin{array}{l}\text { Drugs for management of complications of diabetes } \\
\text { Aldomet } \\
\text { Propranolol } \\
\text { Hydrochlorothiazide } \\
\text { Other anti hypertensive drugs } \\
\text { Lasix } \\
\text { Digoxin } \\
\text { Vitamin }\end{array}$ & $\begin{array}{r}3 / 5 \\
\text { All } \\
2 / 5 \\
2 / 5 \\
\text { All } \\
\text { All } \\
\text { All }\end{array}$ & $\begin{array}{r}18 / 21 \\
4 / 21 \\
19 / 21 \\
7 / 21 \\
17 / 21 \\
\text { None } \\
\text { All }\end{array}$ \\
\hline $\begin{array}{l}\text { Man power } \\
\text { Average number of Doctors } \\
\text { Average number of Nurses } \\
\text { Average number of laboratory technicians }\end{array}$ & $\begin{array}{l}21 \\
64 \\
10\end{array}$ & $\begin{array}{l}2 \\
8 \\
2\end{array}$ \\
\hline
\end{tabular}

HB-Haemoglobin, WBC-White blood counts ESR- Erythrocyte Sedimentation Rate, BUN- Blood urea nitrogen, OHA-Oral antihyperglycaemic agents, HbAlc-Glycohaemoglobine

health centres and hospitals used posters, brochures, pamphlets, group and individual teaching for teaching the diabetic patients.

\section{Demographic profile of diabetic patients (process)}

A total of 229 consecutive diabetic patients, (123 from the selected three referral hospitals and 106 from six health centres) were interviewed. Table 2 indicates that there were more females $(63.8 \%)$ than males $(36.2 \%)$ involved in the study. The age range of the patients was from 15 to 85 years, with mean (SD) $47.9( \pm 15.2)$ and the median 48 years. Among all patients $73(31.9 \%)$ of the patients were illiterate, $65(28.4 \%)$ have completed elementary school, 65 (28.4\%) have attended high school and $23(10 \%)$, have attained college or university education.

Among all patients, $50(21.8 \%)$ of the patients were classified as Type 1 and $179(78.2 \%)$ as Type 2 diabetes cases. About $92 \%$ of the Type 1 and $57 \%$ of the Type 2 diabetes case respectively, had follow ups at hospital or health centre levels. About 68 (29.7\%) had a family history of diabetes (19 reported father, 8 reported mother, 7 reported siblings, 12 reported grand father and 5 children as having a history of diabetes).

The recent mean fasting blood sugar (FBS) value was $190 \pm 89.8 \mathrm{mg} / \mathrm{dl}$, only $21.4 \%$ had values less than 120 $\mathrm{mg} / \mathrm{dl}$.
Table 2: Demographic characteristics of the selected diabetic patients, Addis Ababa, 2003

\begin{tabular}{|c|c|c|}
\hline Characteristics & Frequency & $(\%)$ \\
\hline \multicolumn{3}{|l|}{ Sex } \\
\hline Males & 83 & 36.2 \\
\hline Females & 146 & 63.8 \\
\hline \multicolumn{3}{|l|}{ Education completed } \\
\hline Illiterates & 73 & 31.9 \\
\hline Elementary & 65 & 28.4 \\
\hline High school & 65 & 28.4 \\
\hline College/University & 26 & 11.3 \\
\hline \multicolumn{3}{|l|}{ Type of diabetics } \\
\hline Type 1 & 50 & 21.8 \\
\hline Type 2 & 179 & 78.2 \\
\hline \multicolumn{3}{|l|}{ Family History } \\
\hline Yes & 68 & 29.7 \\
\hline No & 161 & 70.3 \\
\hline \multicolumn{3}{|l|}{ Duration of diabetes } \\
\hline Mean (SD) & $8.1 \pm 7.75$ years & \\
\hline Median & 5 years & \\
\hline Minimum & 1 month & \\
\hline Maximum & 44 years & \\
\hline
\end{tabular}

Diagnosis and treatment profile

Among the 229 patients, 35.4\%, 55.5\% and 9.8\% were identified to be on insulin treatment, oral hypoglycaemic agents, and on dietary control, respectively. One hundred and ten $(89.4 \%)$ of the hospital and $81(76.4 \%)$ of the health centre patients were already undergoing their treatments during the interview period. About $67.2 \%$ of all the patients reported that they were on regular

Ethiop.J.Health Dev. 2005;19(3) 
treatment.

About $65 \%$ of hospital and $60.1 \%$ of health centre patients were symptomatic for diabetes at the time of diagnosis. Out of the total number of patients studied, $43.7 \%$ were first diagnosed at hospitals, $22 \%$ in health centres, $27 \%$ in private laboratories and $5.7 \%$ in clinics respectively (Table 3 ).

Table 3: Diagnosis and treatment profile of the selected diabetic patients in 3 referral hospitals and 6 health centres, Addis Ababa, 2003

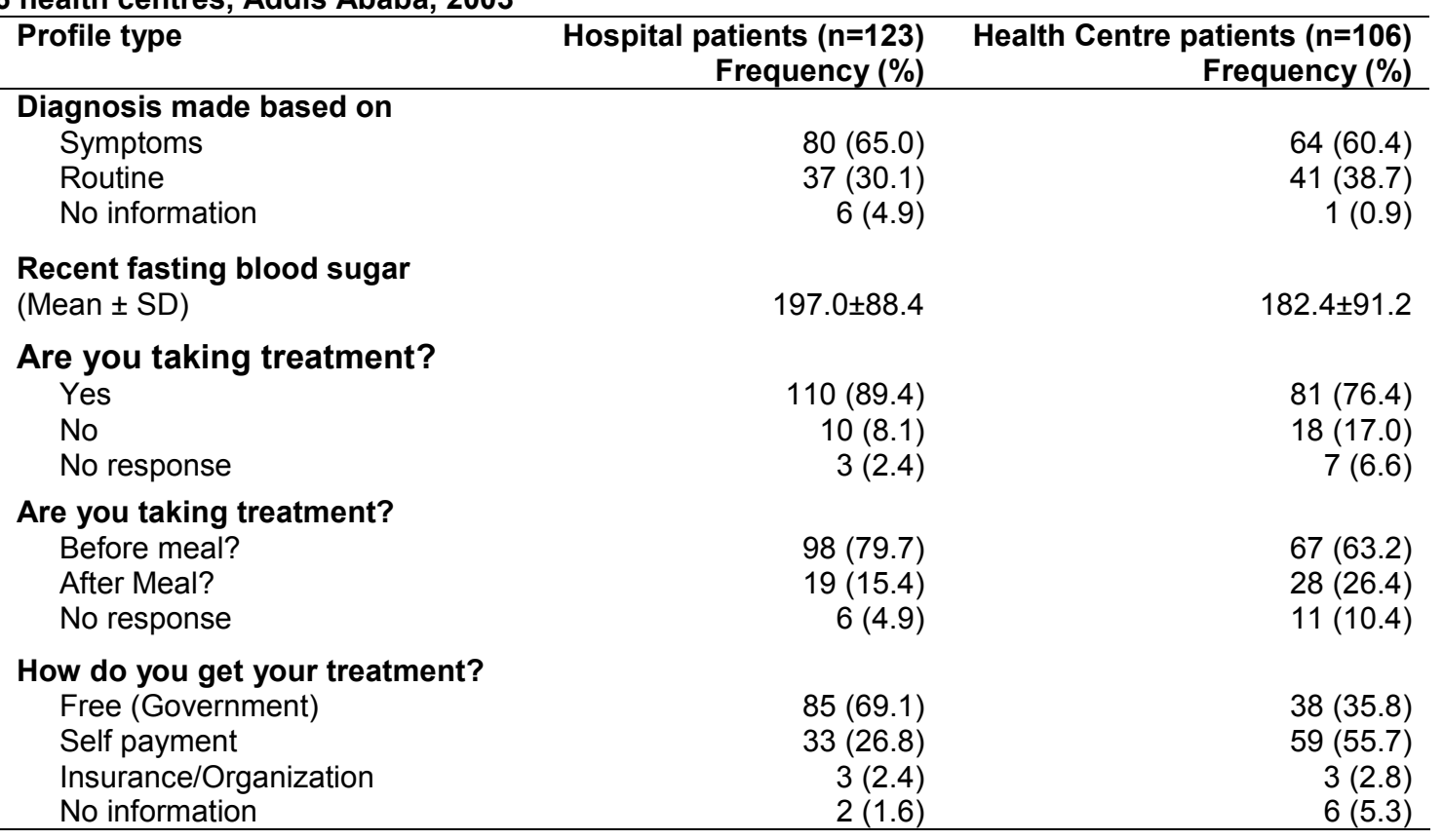

\section{Follow up profile}

Table 4 shows that $199(86.9 \%)$ of the patients had regular follow ups for their diabetes. Among those who had follow ups, $20.6 \%$ have visited health institutions within one month, $61.8 \%$ between one and three months and $13.6 \%$ after three months or more.

Only $21 \%$ of the patients had access for the determination of their blood sugar levels in the same health institutions. Those diabetic patients who had follow ups at hospitals, had more frequent blood sugar determination procedures than patients from the health centres. Only $11(5 \%)$ and three $(1.4 \%)$ of the total number of diabetic patients were able to do self blood glucose monitoring and urine sugar determination respectively at home.

There was no big difference in the compliance to dietary advices among the hospital and health centre patients. About $24 \%$ of the diabetics had attended diabetic education sessions. About $12.7 \%$ of the patients had a follows up to $1-2$ times and $84 \%$ had follow ups of $3-5$ times per year.
Out of the total number of diabetic patients, it was found that $75(32.8 \%)$ knew that blood sugar control decreases complications of diabetes. More than $50 \%$ of the patients didn't undergo urine analysis, BUN Creatinine and lipid profile in the previous 1-2 years.

\section{Out come measures}

Table 5 shows the distribution of the outcomes of diabetes and associated illnesses among diabetic patients. Hypertension and diabetes related eye diseases were found to be the major associated illnesses observed among the diabetic patients. There was no difference between hospital and health centre-treated patients regarding a history of hypertension.

Sixty-six patients (22.8\%), had a total of about 131 admissions of which 51 admissions were diabetes related while 82 admissions were found to be non-diabetic related. Diabetes-related causes of admissions were uncontrolled diabetes in $29(49.2 \%)$, hypoglycaemia in 2 $(3,9 \%)$, renal disease in $3(5.9 \%)$ diabetic ketoacidosis in $13(25.5 \%)$ and others. 
and 6 health centres, Addis Ababa, Ethiopia, 2003

\begin{tabular}{|c|c|c|}
\hline Follow up profile & Frequency & (\%) \\
\hline \multicolumn{3}{|l|}{ Regular follow up } \\
\hline Yes & 199 & 86.9 \\
\hline No & 20 & 11.3 \\
\hline No response & 4 & \\
\hline \multicolumn{3}{|c|}{ Frequency of follow up $(n=199)$} \\
\hline$<1$ month & 41 & 20.6 \\
\hline $1-3$ months & 123 & 61.8 \\
\hline$>3$ months & 27 & 13.6 \\
\hline No response & 9 & 4.0 \\
\hline \multicolumn{3}{|l|}{ Follows diet for control } \\
\hline Yes & 136 & 59.4 \\
\hline No & 93 & 40.6 \\
\hline \multicolumn{3}{|c|}{ Problems related to strict dietary follow up $(n=136)$} \\
\hline Insufficient meal & 69 & 50.7 \\
\hline Lack of diabetic education & 11 & 8.1 \\
\hline Lack of family support & 28 & 20.5 \\
\hline Eating out side of home & 8 & 5.9 \\
\hline Others & 30 & 22.1 \\
\hline \multicolumn{3}{|l|}{ Attended diabetic education } \\
\hline Yes & 55 & 24.0 \\
\hline No & 171 & 74.7 \\
\hline No information & 3 & 1.3 \\
\hline \multicolumn{3}{|c|}{ Number of visits over the last one year } \\
\hline 1-2 times & 29 & 12.7 \\
\hline 3-5 times & 182 & 84.0 \\
\hline No follow up & 6 & 2.6 \\
\hline No information & 2 & 0.9 \\
\hline \multicolumn{3}{|c|}{$\begin{array}{l}\text { knowledge of blood glucose control on prevention } \\
\text { of complication of DM }\end{array}$} \\
\hline Yes & 75 & 32.8 \\
\hline No & 154 & 67.2 \\
\hline \multicolumn{3}{|c|}{ Urine, renal function test over the last $1-2$ years } \\
\hline Yes & 96 & 41.9 \\
\hline No & 116 & 50.7 \\
\hline No information & 17 & 7.4 \\
\hline
\end{tabular}

Table 5: Frequency distribution of outcome of diabetes and associated illness in 229 diabetic patients, Addis Ababa, 2003

\begin{tabular}{lrr}
\hline Disease history & Number & \% \\
\hline Angina & 3 & 1.5 \\
Gout & 10 & 4.4 \\
Peripheral vascular disease & 20 & 8.7 \\
Neurology & 24 & 10.5 \\
Renal disease & 48 & 21.0 \\
Eye problems & 76 & 33.2 \\
Hypertension & 78 & 34.1 \\
\hline
\end{tabular}

\section{Discussion}

The prevalence of non-communicable diseases, particularly diabetes and hypertension, is increasing significantly in developing countries. This indicates the need to make preparations to prevent and to treat those who are affected by the diseases.

All the regional hospitals and one of the health centres in Addis Ababa are running established diabetic referral clinics. Although there is a well-established health infrastructure for diabetics in Addis Ababa, access for blood glucose monitoring at the respective health institutions was very low. Similarly, the emphasis given for diabetic education is low. Nearly $75 \%$ of the patients also required admissions directly or indirectly due to uncontrolled diabetes.

The existing skilled manpower versus the total population coverage per health centres and referral hospitals was found to be very low. The basic equipment required for physical examination are available both at the health centre and hospital levels. But these might not be adequate for a large number of patients $(17,18,19)$.

A study conducted in Egypt by EI-Shazly et al (20) showed that $78 \%$ of the diabetic patients regularly attended the medical centre for follow up as compared to the subjects in this study $(87 \%)$. The referral system in the study area is mainly unidirectional. But a study by Simmons has described the effectiveness of integrated primary and secondary health care diabetic clinics on the metabolic control of diabetic patients (21).

More than half of the patients did not undergo a urine test, or blood urea nitrogen, and creatinine determinations over the last 1-2 years (Table 4 ). The diabetic patients

Ethiop.J.Health Dev. 2005;19(3) 
drawn from the health centre did not have access for lipid profile determinations (Table 1). About $79 \%$ of the patients had a recent FBS measurement that is greater than $120 \mathrm{mg} / \mathrm{dl}$. Eventhough the single FBS value can't determine the level of diabetic control it indicates that most of the diabetic patients had high blood sugar value, which could contribute for high level of Haemoglobin $\mathrm{A} 1 \mathrm{C}(\mathrm{HbAlc})$, which, in turn, is the gold standard used to follow the metabolic control of diabetes (22), but not available in any of the study centres.

The most important reason why diabetic patients have difficulties in undergoing diabetics diet therapy, were the unavailability of adequate meals, lack of support from the family, lack of education on the disease and shortage of money.

Eighty seven percent of the patients said they were visiting their physician regularly (Table 4). Among these, eighty two percent of the patients had followups within three months. However, about $56 \%$ of the diabetics get their blood sugar determinations outside the health institutions where they undergo the follow up. This may indicate that the inconsistency of blood sugar determinations in the hospitals and health centres might have been be a result of the possible shortage of reagents and dextrostics.

The current study showed that self blood sugar determination was performed in only $5 \%$ of the patients, which is lower than the reported $8 \%$ by EI-Shazly et al in Egypt (20). A study by Harris in the USA showed that about $40 \%$ of type 1 and $26 \%$ of type 2 diabetes cases have monitored their blood glucose level daily (23). Ninety five percent of the diabetic patients didn't perform self-blood glucose monitoring at home, $33 \%$ of the patients didn't take their treatments regularly. Such a profile of blood glucose monitoring and inconsistency of intake of treatment predisposes diabetic patients for uncontrolled hyperglycaemia and subsequent development of chronic complications of diabetes. Self blood glucose monitoring and regular treatment with intensive therapy effectively delays the onset and slows the progression of diabetic retinopathy, nephropathy and neuropathy in patients with type 1 and type 2 diabetes $(24,25,26,27)$.

The study also showed that $35 \%$ and $56 \%$ of diabetes cases were treated with Insulin and antihyperglycaemic agents respectively compared to the study by Harris ( $43 \%$ and $49 \%$ respectively)(23).

The study identified the limitations of the access for blood glucose determination, lipid profile, diabetic education, glycated haemoglobin determination and others for the diabetic patients. These makes it difficult to apply the standard medical care for patients with diabetes as per the recommendations of the American Diabetics
Association (28).

A few months prior to the beginning of this study, the Region 14 Health Bureau, in collaboration with the Ethiopian Diabetics Association and the Endocrinology \& Metabolism Unit, of the Dept. of Internal Medicine, Faculty of Medicine, Addis Ababa University, conducted a training program on comprehensive care for diabetic patients. The continuity and sustainability of such initiatives are encouraged, because the management of diabetes requires continuous updates as was shown in studies from Israel and others $(29,30)$.

The fact that about $87 \%$ of the diabetics had regular followups in their respective health centres and hospitals, is very encouraging to strengthen the diabetic education. The non-compliance rate is very few which indirectly reflects their satisfaction with the health care system.

The study has limitations in addressing the details of the outcome measures, because the information obtained from interviewing the patients may not be adequate to conclude the real evidences of chronic complications of diabetes. Nevertheless, hospital admission is one of the out come measures of a disease $(14,15)$. As was shown in the current study, nearly half of the patients were admitted to a hospital because of uncontrolled diabetes and a further quarter of the admissions were because of diabetic ketoacidosis i.e. $75 \%$ of the admissions could be prevented by determining more frequent blood sugar, adjustment of treatment and diabetic education.

What is more important, in the care of diabetic patients is diabetic health education. Shelly et al showed on a Meta analysis and Meta regression study, that patient education intervention improves blood glucose control in adult diabetic patients (29).

This study showed that $24 \%$ of the diabetices have attended health education programs at primary health care levels compared with $97 \%$ as reported by a study from Saudi Arabia (32).

The study has also showed that about $69 \%$ of the cost of diabetic patients is financed by the Government. As the cost of care of diabetes is very high, it will also have an additional impact on the already low socioeconomic status of a country like Ethiopia. A study conducted at the Tikur Anbessa Specialized Hospital in Addis Ababa by Feleke and Enquselassie, showed that the cost of admission of diabetic patients is significantly higher than non-diabetic patients (33). Therefore strengthening diabetic health care at health centres and referral hospital levels would minimize the subsequent burden it has on of budget constraints in the country.

In conclusion, this is the first study undertaken to assess the health care system for diabetic patients in Ethiopia. 
Although there is a well-established health infrastructure for diabetics in Addis Ababa, the status of diabetic care is below the recommended standards. The finding of this study may, thus, help to clarify issues related with potential changes in the health care system dealing with diabetes and strengthen the referral system for diabetes health care. This study may also provide a baseline for conducting further research.

Based on the findings of this study the following recommendations are forwarded:

1. Improving access for more frequent blood sugar determination at health centre and referral hospital levels and introducing Haemoglobin A1c determination at referral hospital levels.

2. Improving the availability of essential drugs e.g. insulin, or to patients at health centre levels or to get their treatment at the referral hospital level.

3. Strengthening diabetic education for primary, secondary and tertiary prevention of diabetes.

4. Improving the number of health professionals and providing short-term courses on diabetes to upgrade the skills of physicians and nurses and facilitating long-term training for Diabetologists/Endocrinologists.

\section{Acknowledgement}

We would like to acknowledge the Ethiopian Science and Technology commission (ESTC) for its financial support. We also thank the Department of Internal medicine and the Research and Ethics Committee of the Faculty of Medicine for their valuable comments and for facilitating the research activity. We thank the Region 14 Health Bureau for facilitating the study and the staff of the respective health Centres and hospitals who participated in the study. We are very grateful to S/r Fikre Mamo, S/r Alemetsehay Yegezu, S/r Mintewab Fekade for their assistance in data collection and Ato Negussu Worku for data entry.

\section{Reference}

1. Roman SH, Harris MI. Management of diabetes mellitus from a public health perspective Endocrinology and Metabolism Clinics of North America. 1997;26:443-473.

2. Gill G, Mbanya JC, Alberti G. Non communicable diseases in the developing world. Diabetes International 1999;9:58.

3. Povilca D. Analysis of Medical admissions to the Armed Force Hospital in Addis Ababa. Ethiop Med J. 1970;8:193-200.

4. Lainovic D. Morbidity study in Dire Dawa Ethiop Med J. 1974;12:13-24.

5. Teferra A, Abdulkadir J. Analysis of medical admissions to Princess Tsehai Memorial Hospital from April 1966 to March 1967. Ethiop Med J. 1968;6:96-102.
6. Lester FT, Tsega E. The pattern of adult medical admissions in Addis Ababa, Ethiopia. East Afri Med J 1976;53:620-34.

7. Seyoum B, Abdulkadir J, Gebregziabher F, Alemayehu B. B. Analysis of diabetic patients admitted to Tikur Anbessa Hospital over eight years period. Ethiop J Health Dev. 1999;13:9-13.

8. Diabetes estimates and Projections. World Health Organization. diabetes@who.int Accessed on Oct. 2003.

9. Gohdes D, Najarian SR, Acton K, Shields R Improving diabetes care in the primary Health Setting: The Indian health service experience Ann Intern Med. 1996;124:149-152.

10. Hiss RG. Barriers to care in non Insulin dependent Mellitus: The Michigan experience. Ann Intern Med. 1996;124:146-148.

11. Berger M, Jorgen SV, Fatten G. Health Care for persons with non Insulin dependent diabetes mellitus. The German experience. Ann Intern Med. 1996;124:153-155.

12. Motalla AA. Diabetes trend in Africa. Diabetes Metab Res Rev 2002;18:s14-20.

13. Okoroa EO, Adejumob AO, Oyejolab BA. Diabetic care in Nigeria: report of a self-audit. Journal of Diabetes and its Complications 2002;16:159-16.

14. Donabedian A. The quality of care. How can it be assessed? JAMA. 1988; 260 :1743-1748.13.

15. Epstein RS, Sherwood LM, From out come research to disease management:A guide for the perplexed. Ann Intern Med 1996;124:832-837.

16. The expert committee on the diagnosis and classification of diabetes mellitus: Report of the Expert Committee on the Diagnosis and Classification of Diabetes mellitus .Diabetes Care. 2000:23 (supp.1):s 4-s19.

17. Federal Democratic Republic of Ethiopia, Ministry of Health: Health Service standards, Health Centre 1996, MOH, Addis Ababa.

18. Federal Democratic Republic of Ethiopia, Ministry of Health: District Hospital Standards, 1998, MOH, Addis Ababa.

19. Federal Republic of Ethiopia Ministry of Health: Specialized Referral Hospital standards 2004, MOH, Addis Ababa(Un published).

20. El-Shazly M, Abdel-Fattah M, Zaki A, Bedwani R, Assad S, Tognoni G, Nicolucci A. health care for diabetic patients in developing countries: A case from Egypt. Public Health. 2000;114:276-81.

21. Simmons D. Impact of an integrated approach to diabetes care at the Rumbalara Aboriginal Health service. Internal Medicine Journal 2003; 33: 581585.

22. Powers Ac, Diabetes mellitus in Braunwald E, Fauci As, Hasper DL. Hauser SL, Longo DL, Jameson JL Harrise principles of Internal Medicine, 15th ed, Newyork, McGraw Jo;; 2--1;2109-2138. 
23. Harris MI. Medical care for patients with diabetes: Epidemologic aspects. Ann Intern Med 1996; 124: 117-22.

24. The effect of intensive treatment of diabetes on the development and progression of long-term complications in insulin dependent mellitus. The Diabetes control and complications trial research group N Engl J Med 1993; 329:977-986.

25. Turner R, Cull C, Holman R, for United Kingdom prospective Diabetes group.United Kingdom prospective diabetes study 17: A 9-year up date of a randomized, controlled trial on the effect of improved metabolic control on complications in noninsulin dependent diabetes mellitus. Ann Intern Med 1996; 124: 132-145.

26. The UK prospective study, Diabetes study. Diabetes 1999;48:1-8.

27. Henry RR, Genuth S. Current recommendations about intensification of metabolic control in noninsulin dependent diabetes mellitus. Ann Intern Med. 1996; 124:175-177.
28. American Diabetic Association. Clinical Practice Recommendation. Standard of Medical Care for Patients with Diabetes Mellitus. Diabetic Care 1997; 20:S1-70.

29. Ukhopadhyay P. Diabetic care in general practice-a survey. J Indian Med Assoc. 2001;99:257-9.

30. Goldfracht M, Porath A. Nationwide program for improving the care of diabetic patients in Israeli primary care centres. Diabetes Care. 2000; 23: 4959.

31. Ellis SE, Speroff T, Dittus RT, Anne Brown A, Pichert JW, Tom A. Elasy TA. Diabetes patient education: A meta-analysis and meta-regression: Patient education and counseling. 2004;1:97-105.

32. Al-Khaldi YM, Al-Sharif. Availability of resources of diabetic care in primary health care settings in Aseer region, Saudi Arabia Ai Saudi Medical Journal 2002; 23:1509-1513.

33. Feleke Y, Enquselassie F. Cost of diabetic care at Tikur Anbessa Specialized Hospital, Addis Ababa, 2005 (on press), 
